\title{
Clinical trials sponsored by industry and other private organizations
}

\author{
Sheila Cavalca CORTELLI(a) \\ Fernando Oliveira COSTA ${ }^{(b)}$ \\ Greyce LOUSANA(c) \\ Paulo Cesar Ribeiro QUINTAIROS(a) \\ Luciana Fávaro \\ FRANCISCONI-DOS-RIOS(d) \\ José Roberto CORTELLI(a) \\ (a) Universidade de Taubaté - Unitau, Office \\ of Graduate Studies and Scientific Affairs, \\ Taubaté, SP, Brazil. \\ (b) Universidade Federal de Minas Gerais - \\ UFMG, School of Dentistry, Periodontics \\ Department, Belo Horizonte, MG, Brazil. \\ (c)Invitare Clinical Research, São Paulo, \\ SP, Brazil. \\ (d) Universidade de São Paulo - USP, School \\ of Dentistry, Department of Operative \\ Dentistry, São Paulo, SP, Brazil.
}

Declaration of Interests: The authors certify that they have no commercial or associative interest that represents a conflict of interest in connection with the manuscript.

Corresponding Author:

Sheila Cavalca Cortelli

E-mail: cavalcacortelli@uol.com.br

Submitted: September 4, 2019

Accepted for publication: September 22,2019

Last revision: June 10, 2020
Abstract: The present manuscript discussed some relevant aspects related to private sponsored clinical trials in dentistry. For decades, the academy has been the major responsible for research in Brazil. Distant from the trade sector, academic research has not always provided clear benefits to society. A key aspect of making benefits clearer is the process of scientific knowledge transference to decision-makers, which is, in fact, the ground of evidence-based dentistry. Although private sponsoring of clinical research seems to be part of the research progress of the business rates, investment in Brazil is lower than those observed in other countries. It is particularly important to understand that instead of creating its own rules, dentistry imported the highquality standards originally designed for pharmaceutical studies. Therefore, it is critical to understand the original rules and how dental items are classified by regulatory agencies. In fact, knowledge about international and local regulation is a basic assumption in industry-sponsored research. Despite globalization, the identification of industry-sponsored studies through open access databases is still very hard and time-demanding. A common concern when conducting industry-sponsored trials is study biases. Fortunately, many relevant organizations, academic and industry groups, have been working seriously against that. Finally, for less experienced researchers, many aspects related to industry-sponsored studies - such as confidentiality, authorship, budget - are deeply discussed until a final version of the trial agreement can be written and signed, protecting all sides. In short, the scenario should be improved, but it already represents a nice opportunity for dental research.

Keywords: Provider-Sponsored Organizations; Industry; Private Sector; Clinical Trial; Support of Research.

\section{Introduction}

Even if society as a whole benefits from the results of research, funding derived from industry and other private organizations to support, it seems to be below average in Brazil. ${ }^{1}$ When this is a fact, there are numerous barriers to overcome. ${ }^{2,3,4}$

The first difficulties stem from common sense about what research sponsorship means. As in any other area, some terms are easily recognized by all directly involved with it, but not for others. Although 
research sponsorship greatly varies, what is usually understood as sponsored research is that there is a company as the sponsor. Industry organizations hire faculty members, academic research foundations, private research institutes, or even their employees to conduct clinical trials in which the main focuses are efficacy and safety of drugs and devices. ${ }^{5}$ Typically, the industry organization designs the protocol and pays for the study conduction. Depending on contractual rules, expertise, and confidence in the final protocol would be the result of both the principal investigator (PI) and industry work. Subsequent barriers then relate to regulation, international guides and local legislation, transfer of evidence to "decision-makers," traceability, biases, and questions regarding publishing, just to say. ${ }^{2,3}$

The different aspects of clinical trials sponsored by industry and other private organizations are thus the subject of this manuscript, derived from a lecture presented at the meeting "Grandes Desafios em Pesquisa Clínica na Odontologia," which gave rise to this Brazilian Oral Research (BOR) supplement.

\section{Regulation}

Comparing to unclear rules, a clearly regulated country as Brazil is more suitable for industry-sponsored studies. By following the timeline, relevant aspects of Brazilian research can be observed (Figure 1).

It is particularly important to understand that clinical trial rules had been designed for pharmaceutical studies. ${ }^{6}$ Later, when dental studies began, global companies with previous expertise imported high-quality standards from those rules. Worldwide, many efforts had been necessary throughout this time (International Council for Harmonization of Technical Requirements for Pharmaceuticals for Human Use $\mathrm{ICH}){ }^{7}$ Years ago, compliance was a major challenge, while cybersecurity, big data, and professionals' data protection have assumed this status today. ${ }^{8}$

Brazilian research maturity has been reinforced by the federal decree No. 9.283 published in $2018,{ }^{9}$ which regulates the law No. 13.243 of $2016 .{ }^{10}$ These documents make institutes of science and technology close to the productive sectors by reducing bureaucracy and government taxes. It also changes how technology is transferred to the private sector of the economy and how partnerships between institutes of science and technology and companies develop. Further, it allows the government to directly contract institutes of science and technology or companies to perform research, development, and innovation. In this context, the academy, industry, funding, and regulatory agencies are learning how to manage all possibilities opened by the decree. Therefore, a higher number of sponsored studies are expected in the next years.

For decades, the academy has been the major responsible for research in Brazil. Distant from the trade sector, academic research has not always provided clear benefits to society: which has become inconceivable. Private sponsoring thus seems to be part of research progression. At this time, tendencies for refundable grants reveal that this important change had already started. Overall, this type of funding avoids waste of time and money and unnecessary exposition of patients to interventions that would never become a real-life therapeutic option.

Figure 2 shows comparative data about the percentage of gross domestic product (GDP) invested in research, development, and technology by countries among G20 based on UNESCO (United Nations Educational, Scientific, and Cultural Organization). ${ }^{11}$ The vertical depth of the bars represents the countries' GDP; the width of the bars represents the percentage of invested GDP, while the area of each block is proportional to the overall GDP spent on research. Values indicate that despite Brazil's low GDP, the Brazilian government invests similar percentages in comparison to other countries such as Canada, Italy, and the United Kingdom. It means that if the Brazilian economy increases, more money would be available with the same percentage. A comparison of Japan and Brazilian blue bars illustrates it. On the other hand, red bars indicate greater business investment by countries other than Brazil: it is just to compare Brazilian and Australian referred bars. Hence, considering countries recognized as knowledge producers, such as Germany, the decree mentioned above indicates that Brazilian regulations are in the right direction and that this research field can develop a lot. More specifically, there is a need to understand how each dental item to be investigated is classified by regulatory 


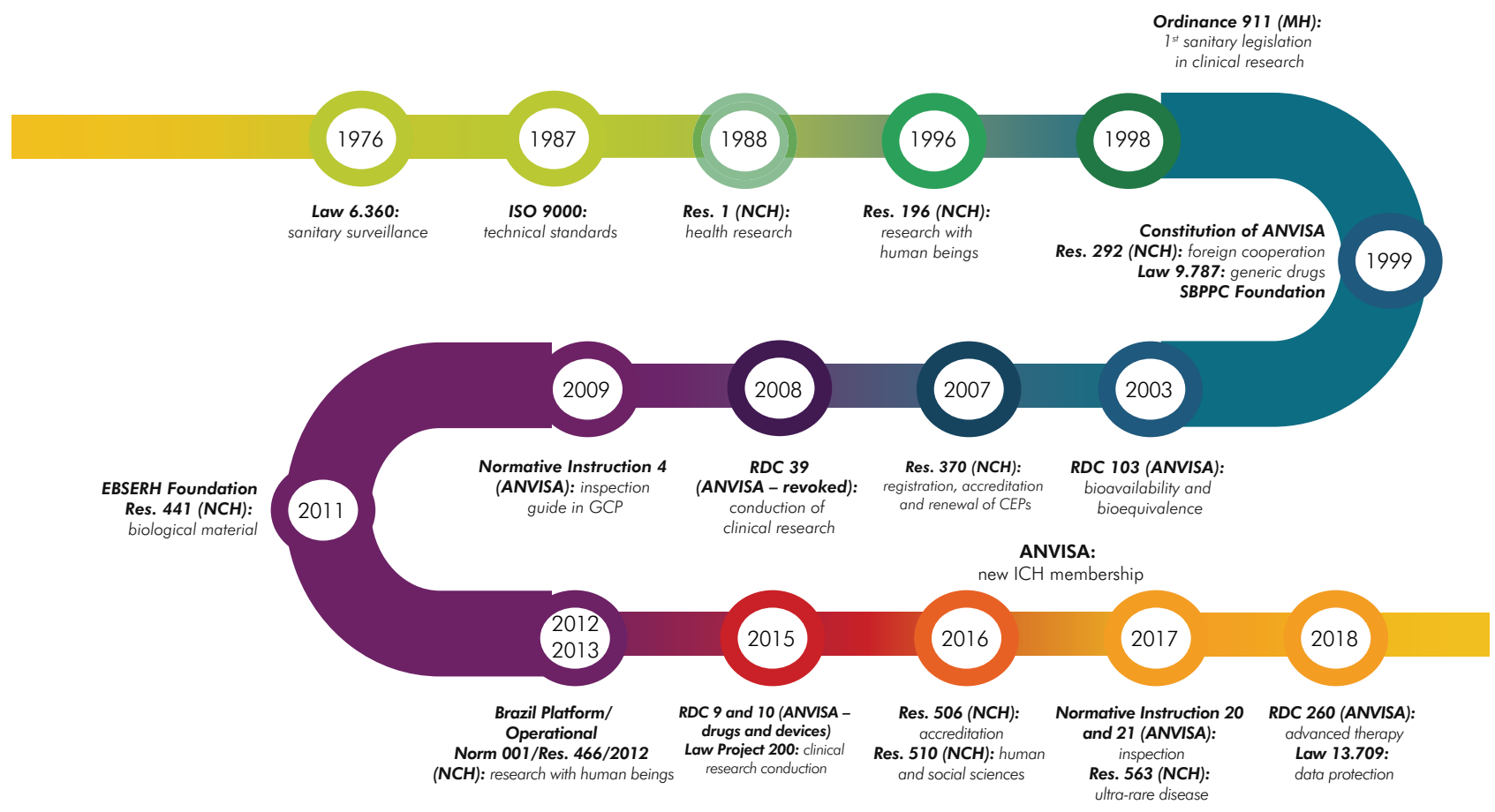

EBSERH: Brazilian Company of Hospital Services; GCP: good clinical practices; M.H.: Ministry of Health; NCH: National Council of Health; N.I.: normative instruction; RDC: resolution of the collegiate board; Res.: resolution; SBPPC: Brazilian Society of Professionals in Clinical Research.

Figure 1. Brazilian Clinical Research Timeline. In Brazil, Clinical Research is an area in constant evolution, regulated by ethical and regulatory instances. The national ethics system, composed by the National Commission for Ethics in Research (CONEP) and the Research Ethics Committees (RECs), was introduced in 1996 through Resolution No. 196, subsequently revoked by Resolution No. $466 / 2012$, and it is based on the main international documents which issued declarations and guidelines about research involving human beings: Nuremberg Code (1947), Helsinki Declaration (1964 and its later versions of 1975, 1983, 1989, 1996, 2000, 2008, and 2013), the International Covenant on Civil and Political Rights (ONU, 1966), and the Universal Declaration on Bioethics and Human Rights, in 2004. Since its creation, dozens of resolutions, operational standards, and circular letters were published, focusing on the operationalization of the system and guarantee of rights, well-being, and protection of research participants, such as the Resolution No. 370/2007, which deals with registration, accreditation, and renewal of RECs, the Operational Standard No. 001 , about the organizations and operation of REC/CONEP system and the procedures for submission, evaluation, and monitoring of research involving human beings, the Resolution No. 510/2016, which brings specific regulations for research in Social and Human Sciences and Resolution No. 563/2017, which deals with the post-study access right of participants with ultra-rare diseases. A bill No. 200/2015 (current No. 7.082/2017) has been in progress since 2015, bringing changes to several aspects of the national ethics system in research projects, including the establishment of a new body to review and authorize protocols. From the regulatory point of view, long before the establishment of the largest regulatory agency in the country - Brazilian Health Surveillance Agency (ANVISA) -, the regulation of products for human use, such as drugs and pharmaceuticals supplies, for example, was already a concern in Law No. 6.360 of 1976. More than 10 years have passed until the publication of Resolution No. 1/88, the first one to standardize health research. In 1999, the same year in which the Brazilian Society of Professionals in Clinical Research (SBPPC) was founded, ANVISA was created, aiming at the protection and promotion of health for Brazilian citizens through the regulation of health products and services. Since 2013, ANVISA has been working on the regulation for clinical trials with drugs, devices, and advanced cell therapies. In March 2015, ANVISA published two resolutions, changing the submission process in Brazil. Resolutions RDC No. 09/2015 (for clinical trials with drugs) and RDC 10/2015 (for clinical trials with devices) started a process similar to the Investigational New Drug (IND) process of the U.S. Food and Drug Administration (FDA). In 2016, ANVISA was accepted as a new member of the International Conference on Harmonization of Technical Requirements for Registration of Pharmaceutical Products for Human Use (ICH). Revoking N.I. No. 4/2009, the normative instructions No. 20 and 21 were published in 2017, regulating procedures of inspection in Good Clinical Practices for clinical trials with drugs and medical devices, respectively. In 2018, RDC No. 260 was published, determining rules for clinical trials with advanced therapy products and establishing a regulatory mark about the topic. In the same year, reflecting concerns about transparency in handling and storage of personal data comes Law No. 13.709, also known as Brazilian General Data Protection Law, applied to both individuals and legal entities, aiming at guaranteeing privacy and data protection to users of several services, including the research participant. 
agencies in a given country. Dental implants would be tested as health devices in Brazil, while oral hygiene products will be tested as cosmetics. One should also verify if the most novelty seen in a dental meeting is already registered in his/her country. Knowledge about international and local regulation is a basic assumption in industry-sponsored research.

\section{International guides and local legislation}

When talking about industry-sponsored clinical trials, international standards, rules, and guidelines are mandatory. Authors encourage readers to visit the International Council for Harmonization - ICH website (https://www.ich.org/home.html). ${ }^{12}$ The most widely known guideline is the E6 related to good clinical practice. However, this is only one among nineteen related to efficacy. In fact, ICH guidelines are organized into four main blocks. The efficacy block is the largest one composed of 19 guidelines, the quality one, of 14, while the safety and the multidisciplinary blocks are both composed of 11 guidelines each.

\section{Evidence transfer to "decision makers"}

Evidence-based dentistry (Figure 3) and real-life evidence also trigger industry-sponsored studies. Evidence-based dentistry integrates the dentist's clinical

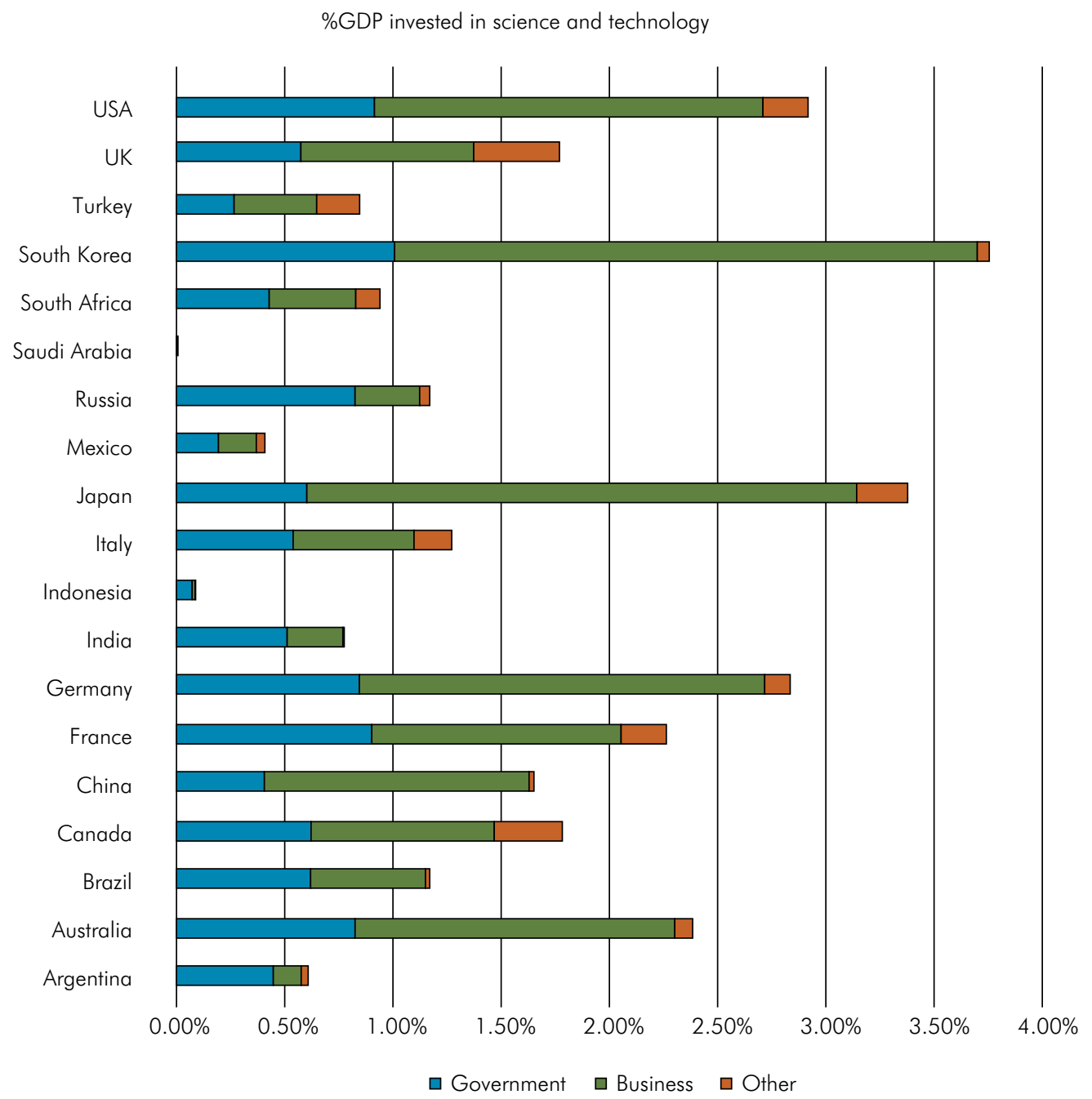

Figure 2. Public and private funding of science and technology in the G20 country group. Data from UNESCO - United Nations Educational, Scientific, and Cultural Organization. ${ }^{11}$ 
expertise, the patient's needs and preferences, and the most current, clinically relevant evidence improving the decision-making process for patient care (American Dental Association - ADA). The Nature group owns a specialized scientific publication aiming at helping clinicians to find the best evidence and to guide their dental practice through specialist comments. ${ }^{13}$ Also, to provide registration and quality seals, regulatory agencies demand results from studies conducted with the most user representative population.

Lavis et al. ${ }^{14}$ grouped into five key questions the results about the effective transference of research knowledge to decision-makers (Figure 4).

Question 1: What Should Be Transferred to Decision Makers? Considering that individual studies can often lead to a conclusion quite different from systematic review research and professional organizations should transfer messages derived from a body of evidence.

Question 2: To Whom Should Research Knowledge Be Transferred? Messages from the body of evidence should match the audience. It needs being clear enough for patients, clinicians, managers, or public policymakers.
Question 3: By Whom Should Research Knowledge Be Transferred? Knowledge-transfer will be successful if the messenger has credibility. Key opinion leaders, health care colleagues, and health organizations are widely used as credible messengers that increase adherence to clinical practice guidelines.

Question 4: How Should Research Knowledge Be Transferred? Transference of knowledge is more effective by interactive processes in comparison to passive processes regardless of the audience.

Question 5: With What Effect Should Research Knowledge Be Transferred? Transfer measures should be able to identify in which degree decision-making processes of each target audience are influenced by research knowledge.

\section{Traceability}

Despite an expected increase in industrysponsored studies, these numbers would only be trackable if editors and scientific journals demand that authors disclosure such information. Nowadays, it is very hard and time demanding to identify industry-sponsored studies in online databases.

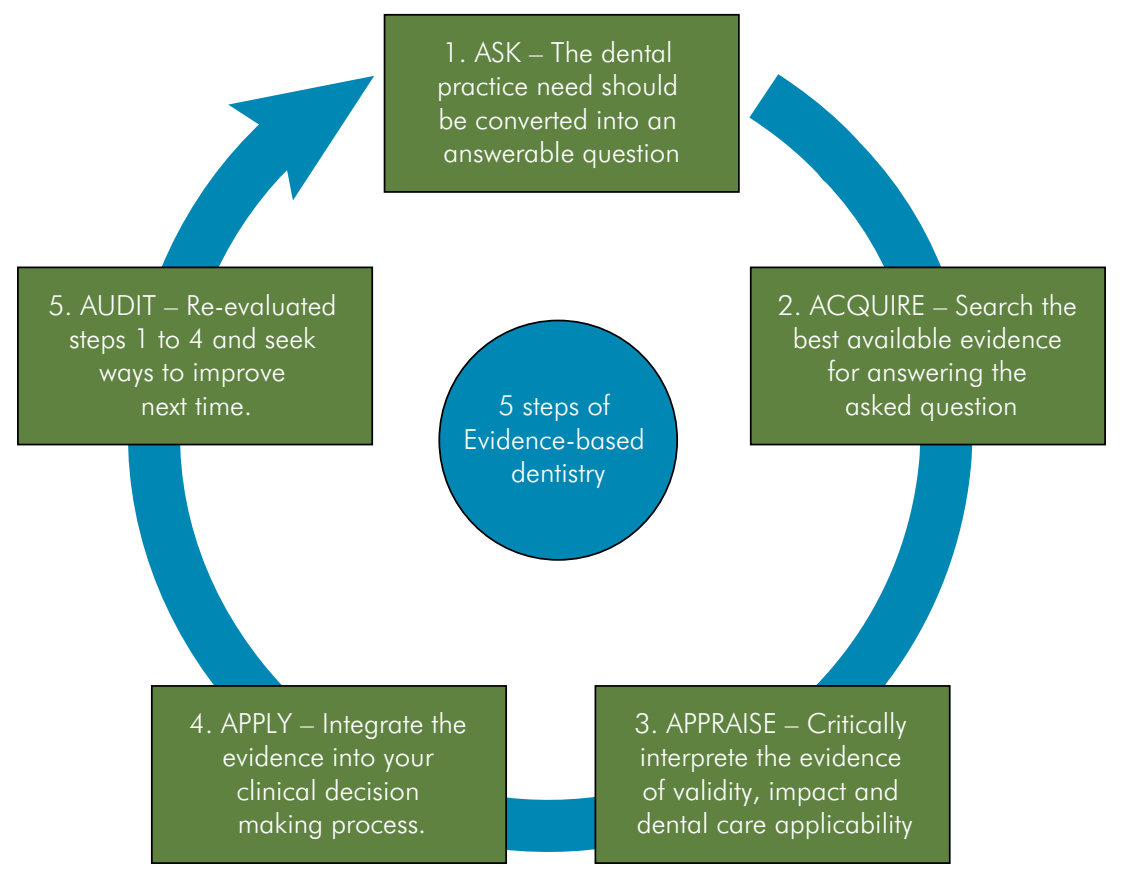

Figure 3. A decision-making process that supports evidence-based dentistry. 


\begin{tabular}{|l|c|c|c|c|c|}
\hline & $\begin{array}{c}\text { Question 1 } \\
\text { WHAT? }\end{array}$ & $\begin{array}{c}\text { Question } \\
\text { TO WHOM? }\end{array}$ & $\begin{array}{c}\text { Question } \\
\text { BY WHOM? }\end{array}$ & $\begin{array}{c}\text { Question } 4 \\
\text { HOW? }\end{array}$ & $\begin{array}{c}\text { Question } \\
\text { WITH WHAT EFFECT? }\end{array}$ \\
\hline $\begin{array}{l}\text { Transference } \\
\text { of evidence to } \\
\text { decision-makers }\end{array}$ & $\begin{array}{c}\text { Body of evidence } \\
\text { instaed of isolate } \\
\text { studies }\end{array}$ & $\begin{array}{c}\text { Clear enough for } \\
\text { each audience: } \\
\text { patients, clinicians, } \\
\text { public policemakers }\end{array}$ & $\begin{array}{c}\mathrm{KOL} \text {, health care } \\
\text { colleagues and } \\
\text { health organizations }\end{array}$ & $\begin{array}{c}\text { Interactive processes } \\
\text { regardless audience }\end{array}$ & $\begin{array}{c}\text { Measurements should be } \\
\text { able identify in which } \\
\text { degree making decision } \\
\text { processes of each target } \\
\text { audience are influence by } \\
\text { research knowledge. }\end{array}$ \\
\hline
\end{tabular}

$\mathrm{KOL}$ : key opinion leader.

Figure 4. Chart of key questions of effective transfer of research knowledge according to Lavis et al. ${ }^{14}$

After visiting http://www.ensaiosclinicos.gov. br, we failed to retrieve the number of registered protocols related to the industry. Although searching on https://clinicaltrials.gov - using "dental," "oral," and "periodontal," plus "industry" as key words it worked better, but it was far from ideal.

In the past 15 years, there was increased attention to the source of funding, author affiliation, and conflict of interests, meaning that it is more difficult to capture whether research had been sponsored by industry or not before that time. Not all journals in the field of dentistry clearly report this data. In fact, the scenario is complex because rates of participation showed by both academia and industry vary a lot throughout the scientific process. Sometimes, the great idea and the protocol born in academia and through an investigator initiative research grant or an independent investigator grant researchers get funds to support their research. In a second hypothetical example, universities support researchers and their research for years until the prototype stage. From this point, to become a market drug or device, research still demands a huge amount of money. The way out is to find a private sponsor, such as an industry. Companies also pay academic personnel to solve their problems and improve their processes through scholarships that are not always disclosed in a scientific publication. Further, language use can differ between academia and industry research reports influencing the readers' perception.

Cepeda et al. ${ }^{15}$ found differences regarding the result descriptions by industry-affiliated authors compared to non-industry-affiliated authors. Words and expressions showed a relation to the authors' affiliation. Academia conducts studies to answer all types of questions, while the industry has its main focus on drugs and devices. Again, a fact that influences the readers' perception on data availability. Finally, although important to regulatory agencies to be aware of numbers and types of studies being conducted, academia is not close to them. Usually, academic studies in Brazil are not informed to the Brazilian Health Regulatory Agency (ANVISA). It is a lost opportunity for joining efforts to improve health research.

\section{Biases}

On the other hand, inappropriate behavior is wide. It may happen occasionally and inadvertently, but it could be very serious as well. Here, examples given by the United Kingdom Research Council ${ }^{16}$ will be cited: they have weak procedures, inadequate documentation, informed consent forms not properly obtained, lack of explicitly and transparency, improper conduction in peer review, negligence, breach of confidentiality, placing participants in danger without their consent, or appropriate safeguards even with consent is provided, undisclosed duplication of publication, manufacturing, falsification, and plagiarism.

Lundh et al. ${ }^{5}$ evaluated cross-sectional studies, cohort studies, systematic reviews, and meta-analyses that quantitatively compared primary research studies of drugs or medical devices sponsored by industry with studies with other sources of sponsorship without language restrictions. The authors discussed several possible factors that can explain the relationship between industry funding and favorable outcomes, 
and they concluded that, in general, there is evidence for the existence of industry bias in studies. However, the body of evidence for device studies is not as strong as for drug studies. In implant dentistry, Popelut et al. $(2010)^{17}$ found that both industry-sponsored and trials with an unknown funding source had lower annual failure rates compared to non-industry associated trials. These authors emphasized that at that time, most studies were observational instead of interventional. Schwendicke et al. ${ }^{18}$ assessed the effects of industry sponsorship on the design, comparator choice, and results of randomized controlled trials on dental restorative materials. The proportion of trials comparing against gold standard restorative or adhesive materials did not differ between the trial types. The need for retreatment showed similar rank values when comparing sponsored and nonsponsored trials. More recently, Dos Santos et al. ${ }^{19}$ did not detect significant bias in industry-sponsored clinical trials regarding dental implants.

Fabbri et al. ${ }^{20}$ evaluated industry-sponsored studies and their influence on research agendas in any field. The authors observed the influence on research agendas and indicated the need for strategies to counteract the industry influence. Kearns, Glantz, and Schmidt ${ }^{21}$ analyzed previously undocumented internal cane and sugar beet industry documents from 1959 to 1971 to evaluate industry actions related to setting research priorities for the National Caries Program from the National Institute of Dental Research. Authors reported a negative influence by the sugar industry on research priorities agenda. Despite the knowledge of the sugar role in tooth decay, the sugar industry adopted a strategy to deflect attention to public health interventions that would reduce the harm of sugar consumption, rather than restricting intake. If this data exemplifies a source of bias, this is quite different from the widely questioned research sponsored by industry. In fact, past findings like that triggered significant changes in research worldwide. In comparison to that time, research rules became clearer and easier to track. This also changed consumers and professionals, which became more conscious and critical.

Two years ago, the ADA and the Task Force on Design and Analysis in Oral Health Research joined experts - in the conference Is that research trustworthy? - to discuss whether there is a problem with bias in sponsored research or not, which tools could be applied to minimize bias in research, and daily use of evidence in dental care. ${ }^{22,23}$ The task force on Design and Analysis in Oral Health Research is a non-profit organization that has made numerous contributions to dental research, and that is composed of individuals from universities, private research centers, government, and industry. ${ }^{24}$ Besides ADA, the U.S. Food and Drug Administration (FDA), the National Institute of Dental and Craniofacial Research, the American Association for Dental Research (AADR) and industry experts were the speakers at the conference. Experts said, "there are safeguards in place to ensure that research published in most peer-reviewed journals today is scientifically sound and unbiased." The speaker, Dr. Steven Offenbacher, brought to the discussion that "clinical trials are complicated affairs." During the conference, aspects related to research transparency were also discussed.

The International Committee of Medical Journals Editors (ICJME) authorship recommendation $\mathrm{s}^{25}$ are intended to ensure that credit is given under substantial contribution. However, these recommendations do not distinguish the quantity and quality of contribution. Authorship confers credit and has important transparency implications. Therefore, ICJME is favorable to editorial policies that require the disclosure of the authors' contributions. A fact that is worth considering is affiliation. Although predictive affiliation does not guarantee that a relationship between industry and research is accessible. The disclosure of conflicts of interest also influences research transparency. According to the ICJME, financial relationships are the most easily identifiable conflicts of interest and the most likely to undermine the credibility of the journal, the authors, and science itself. However, there are conflicts harder to identify, such as personal rivalries and intellectual beliefs. Also, confidentiality plays a role in different ways. Matters of contractual aspects under premature breaches could impair journals/ researchers' trust and could promote unethical participant's exposure. In addition, for industry- 
sponsored studies, it could represent a significant loss of investments, patentable knowledge, or market share. Confidentiality may have to be breached if participants are under danger, dishonesty, or fraud is alleged.

\section{Questions regarding publishing}

Apart from making research with high ethical and quality standards, data publishing is one of the most valued achievements of academia. Faculty members are frequently asked about unpublished data. The expression "publishes or perish" belongs to their daily life. Objectives of industry-sponsored studies are usually wide, but sometimes quite simple, such as consumer's choice regarding color, flavor, or smell. For regulatory reasons, phase IV studies would never end considering that drugs, materials, procedures should continuously prove their safety and efficacy in people who are deeply changing. For most high-quality peer-review journals, these studies tend to be classified as "confirmatory," "without innovation," having, therefore, a low chance of acceptance for publication due to possible negative influence on the journal's impact factor.

Beyond that, a private sponsor of a clinical trial may want derived results to be kept confidential for some time, or own its intellectual property, making the publication of a paper with good potential of acceptance unfeasible. Hence, principal investigator (PI), University, or clinical research center responsible, and the sponsor should talk over among themselves and sign a contract that covers all involved parts. The trial agreement would establish if, and how, also concerning authorship, results will be publicized. It is relevant to remind readers that each part has the same right regarding whether a given trial agreement would be signed or not. ${ }^{26,27}$

If the academy does not deem ethical to conduct research and does not disclose its results, regardless of whether they are favorable or not, and this is a clause established by the sponsor, the contract should not be signed. It is worthy of being aware, in this case, that ethics, on principle, requires publicity of the study, not properly its publication: publicity may be reached by registering the trial protocol in a specific online platform (ClinicalTrials.gov, for instance), by presenting the protocol or results in an event and so on, and not necessarily by publishing a scientific paper/manuscript. In the contract, it would also be interesting to determine who will be the responsible for a potential patent derived from industry-sponsored research, and what kind and percentage of participation each of those involved will have in the profits from it. ${ }^{28,29}$

\section{Other possibilities}

Besides government or industry funding, the crowdfunding system may be an alternative to make research feasible nowadays. Systems like that usually consist of web platforms by which is possible to present a research project or innovative idea, and it receives contributions worldwide. All people connected to the platform are eligible contributors that completely voluntarily decide whether they would invest money or not. The project proponent can establish the own project rules, including the type of contribution and minimal or maximal values. Besides, the proponent establishes how investors would be compensated in the future. Typically, compensations are done by paying the money back, or by providing services or courtesy products, such as samples of the developed product. Crowdfunding is also used without compensation. As an example, we can mention donations for specific health care procedures. In Brazil, Vakinha is a wellknown crowdfunding web platform accessible at https://www.vakinha.com.br.

The term "Angel Investor" generally refers to a high net-worth individual who typically invests in small, private firms on his or her own account. ${ }^{30}$ Worldwide, famous people and billionaires have been considered health care as valuable investments, especially when they know diseased relatives, fans, or social media followers.

There are also other types of funds that could be considered when talking about research sponsorship. After experiencing a 3.6\% decline in its GDP in 2016, the Brazilian economy started to grow again in 2017 with the expectation of growth of more than $1 \% .{ }^{31}$ Therefore, 
mutual industry funds in Brazil is also growing. In the market, there are many credit lines opened that are attractive for both industry and academic researchers since they work in collaboration..$^{31}$ Also, to improve the local economy, some markets have been creating their own funds, which could be asked to sponsor clinical research. For example, some kind of natural active ingredient could be so far from an ad hoc reviewer of government funding research agencies and, at the same time, so close to local farm producers. In this case, the latter can decide to sponsor the active ingredient research from preclinical to clinical studies.

\section{Conclusion}

Conducting clinical trials sponsored by industry and other private organizations is indeed promising, despite the many - and new day after day - challenges to overcome.

Attention to this issue is thus crucial so that Brazil resembles other countries that stand out in respectable - clinical - research, largely made feasible, not by the government, but by industry and other private organizations.

\section{Acknowledgements}

The authors thank Lidiane Zito Grund and Anna Carolina Parracho Motzko Soares for their technical assistance with figure 1; the Scientific Committee of the meeting "Grandes Desafios em Pesquisa Clínica na Odontologia," in which the lecture that originated this manuscript was presented, the funding sources of the event (Coordination for the Improvement of Higher Education Personnel CAPES \#88887.290888/2018-00 Public Notice 29/2018, Dean's Office for Research Studies/University of São Paulo - PRP/USP \#2018.1.852.23.5 and School of Dentistry Foundation/Foundation for Scientific and Technological Development of Dentistry - FFO/ Fundecto); and Professor Giuseppe Alexandre Romito, editor-in-chief of the Brazilian Oral Research - BOR, for agreeing with the publication of each eventderived lecture in this supplement. They declare there are no potential conflicts of interest concerning the authorship and/or publication of this article.

\section{References}

1. Nakabashi L. Aproveitamento de pesquisas em universidades pode ser maior. Jornal da USP; 2019 Jun 19 [cited 2019 Jun 19]. Available from: https://jornal.usp.br/atualidades/aproveitamento-de-pesquisas-em-universidades-pode-ser-maior/

2. Handen JS, Patrick DW. 3 major challenges with global clinical trials: and how to overcome them. Clinical Leader. 2018 Aug 2 [cited 2019 Jul 11]. Available from: https://www.clinicalleader.com/doc/major-challenges-with-global-clinical-trials-andhow-to-overcome-them-0001

3. Burrows A. Report: The 8 biggest challenges facing clinical trial professionals. Informaconnect; 2016 Nov 30 [cited 2019 Jul 11]. Available from: https://knect365.com/clinical-trials-innovation/article/e414c9b9-8de9-4525-8fe6-fe6264d36df0/report-biggestchallenges-clinical-trials-pt-1

4. Institute of Medicine (US). Forum on Drug Discovery, Development, and Translation. Transforming clinical research in the United States: challenges and opportunities: workshop summary. Washington, DC: National Academies Press; 2010.

5. Lundh A, Lexchin J, Mintzes B, Schroll JB, Bero L. Industry sponsorship and research outcome. Cochrane Database Syst Rev. 2012 Dec;12:MR000033. https://doi.org/10.1002/14651858.MR000033.pub2.

6. Organização Panamericana da Saúde - OPAS. Boas práticas clínicas: documento das américas. IV Conferência Pan-Americana para Harmonização da Regulamentação Farmacêutica; 2005 Mar 2-4; mar. 2005; República Dominicana. [place unknown]: Organização Panamericana da Saúde; 2008. [cited 2019 Jul 12]. Available from: https://hrac.usp.br/wp-content/uploads/2016/04/documento_ americas_organizacao_panam_.pdf

7. International Council for Harmonisation of Technical Requirements for Pharmaceuticals for Human Use (ICH) [homepage]. International Council for Harmonisation of Technical Requirements for Pharmaceuticals for Human Use (ICH); 2018 [cited 2019 Jun 2]. Available from: https://ebd.ada.org/en

8. Shaw B, Whitney P. Ethics and compliance in global pharmaceutical industry marketing and promotion: the role of the IFPMA and self-regulation. Pharm Policy Law. 2016;18(1-4):199-206. https://doi.org/10.3233/PPL-160443 
9. Brasil. Decreto $n^{\circ}$ 9.283, de 7 de fevereiro de 2018. Regulamenta a Lei $n^{\circ} 10.973$, de 2 de dezembro de 2004, a Lei $n^{\circ} 13.243$, de 11 de janeiro de 2016, o art. 24, $\S 3^{\circ}$, e o art. 32, $\S 7^{\circ}$, da Lei n ${ }^{\circ} 8.666$, de 21 de junho de 1993, o art. $1^{\circ}$ da Lei $n^{\circ} 8.010$, de 29 de março de 1990, e o art. $2^{\circ}$, caput, inciso I, alínea " $g^{\prime \prime}$, da Lei $n^{\circ}$ 8.032, de 12 de abril de 1990, e altera o Decreto n 6.759 , de 5 de fevereiro de 2009, para estabelecer medidas de incentivo à inovação e à pesquisa científica e tecnológica no ambiente produtivo, com vistas à capacitação tecnológica, ao alcance da autonomia tecnológica e ao desenvolvimento do sistema produtivo nacional e regional. Diário Oficial União. 8 Feb 2018.

10. Brasil. Lei no 13.243, de 11 de janeiro de 2016 Dispõe sobre estímulos ao desenvolvimento científico, à pesquisa, à capacitação científica e tecnológica e à inovação e altera a Lei n 10.973 , de 2 de dezembro de 2004, a Lei n 6.815, de 19 de agosto de 1980, a Lei $n^{\circ}$ 8.666, de 21 de junho de 1993, a Lei n 12.462 , de 4 de agosto de 2011, a Lei no 8.745, de 9 de dezembro de 1993, a Lei $n^{\circ} 8.958$, de 20 de dezembro de 1994, a Lei n 8.010, de 29 de março de 1990, a Lei n 8.032, de 12 de abril de 1990, e a Lei n 12.772 , de 28 de dezembro de 2012, nos termos da Emenda Constitucional n 85, de 26 de fevereiro de 2015. Diário Oficial União. 12 Jan 2016.

11. Scienceogram UK. Global private and public R \&D funding. 2013 [cited 2019 June 2]. Available from: https://scienceogram.org/ blog/2013/05/science-technology-business-government-g20/

12. ICH Harmonsaiton for Better Health. Ich guidelines. 2019 [cited 2019 Jun 4]. Available from: https://www.ich.org/page/ich-guidelines

13. Nature. Evidence-based dentistry. London: Springer Nature; 2019 [cited 2019 Jun 4]. Available from: https://www.nature.com/ebd/

14. Lavis JN, Robertson D, Woodside JM, McLeod CB, Abelson J. How can research organizations more effectively transfer research knowledge to decision makers? Milbank Q. 2003;81(2):221-48, 171-2. https://doi.org/10.1111/1468-0009.t01-1-00052

15. Cepeda MS, Berlin JA, Glasser SC, Battisti WP, Schuemie MJ. Use of adjectives in abstracts when reporting results of randomized, controlled trials from industry and academia. Drugs R D. 2015 Mar;15(1):85-139. https://doi.org/10.1007/s40268-015-0085-9

16. United Kingdom Research Council. RCUK policy and guidelines on governance of good research conduct. United Kingdom Research Council; 2017 [cited 2019 Jun 4]. Available from: https://www.ukri.org/files/legacy/reviews/grc/rcuk-grp-policy-and-guidelinesupdated-apr-17-2-pdf/

17. Popelut A, Valet F, Fromentin O, Thomas A, Bouchard P. Relationship between sponsorship and failure rate of dental implants: a systematic approach. PLoS One. 2010 Apr 21;5(4):e10274. https://doi.org/10.1371/journal.pone.0010274

18. Schwendicke F, Tu YK, Blunck U, Paris S, Göstemeyer G. Effect of industry sponsorship on dental restorative trials. J Dent Res. 2016 Jan;95(1):9-16. https://doi.org/10.1177/0022034515609270

19. Dos Santos MBF, Agostini BA, Moraes RR, Schwendicke F, Sarkis-Onofre R. Industry sponsorship bias in clinical trials in implant dentistry: systematic review and meta-regression. J Clin Periodontol. 2019 Apr;46(4):510-9. https://doi.org/10.1111/jcpe.13100

20. Fabbri A, Lai A, Grundy $Q$, Bero LA. The influence of industry sponsorship on the research agenda: a scoping review. Am J Public Health. 2018 Nov; 108(11):e9-16. https://doi.org/10.2105/AJPH.2018.304677

21. Kearns CE, Glantz SA, Schmidt LA. Sugar industry influence on the scientific agenda of the National Institute of Dental Research's 1971 National Caries Program: a historical analysis of internal documents. PLoS Med. 2015 Mar 10;12(3):e1001798. https://doi.org/10.1371/journal.pmed.1001798

22. American Dental Association. Center for Evidence-Based Dentistry. Evidence. Chicago: American Dental Association; 2018 [cited 2019 Jun 2]. Available from: https://ebd.ada.org/en/evidence

23. Manchir M. Is that research trustworthy? Conference looks at using clinical trials outcomes in practice. Chicago: American Dental Association; 2016 [cited 2019 Jun 3]. Available from: https://www.ada.org/en/publications/ada-news/2016-archive/ december/is-that-research-trustworthy-conference-looks-at-using-clinical-trials-outcomes-in-practice

24. Task force on Design \& Analysis in Oral Health Research. Homepage. 2018 [cited 2019 Jun 2]. Available from: http://taskforceondesign.org

25. International Committee of Medical Journals Editors. Defining the role of authors and contributors. [homepage]. International Committee of Medical Journals Editors; 2019 [cited 2019 Jun 5]. Available from: http://www.icmje.org/recommendations/ browse/roles-and-responsibilities/defining-the-role-of-authors-and-contributors.html

26. Sampat K. 9 essential components of a clinical trial agreement. Clinical Trials Arena; 2017 [cited 2019 Jul 11]. Available from: https://www.clinicaltrialsarena.com/news/9-essential-components-of-a-clinical-trial-agreement-5885280-2/

27. The Ohio State University. Center for Clinical and Translational Science. Clinical trial agreement: managing the relationship between a study sponsor and an institution. 2019 [cited 2019 Jul 11]. Available from: https://ccts.osu.edu/content/clinical-trial-agreement

28. Ilie L. Intellectual property rights: an economic approach. Procedia Econ Finance. 2014;16:548-52. https://doi.org/10.1016/S2212-5671(14)00837-5

29. Jacob M, Hellström T, Adler N, Norrgren F. From sponsorship to partnership in academy-industry relations. R\&D Manag. 2000;30(3):255-62. https://doi.org/10.1111/1467-9310.00176

30. Wong A, Bhatia M, Freeman Z. Angel finance: the other venture capital. Strateg Change. 2009;18(7-8):221-30. https://doi.org/10.1002/jsc.849

31. Mutual Funds Industry in Brazil. [cited 2019 Jul 12]. Available from: https://www.google.com.br/search?hl=pt-BR\&as_q=\&as_ep $q=$ Mutual +Funds +Industry+in+Brazil.+\&as_oq $=\& a s_{-} e q=\& a s_{-} n l o=\& a s_{-} n h i=\& \mid r=\& c r=\& a s_{-} q d r=a l l \& a s_{-} s i t e s e a r c h=\& a s$. occt $=$ any\&safe $=$ images\&as_filetype $=\& t b s=$ 